\title{
Clinical study on repair of metacarpal bone defects using titanium alloy implantation and autologous bone grafting
}

\author{
YUE ZHENG $^{1}$, JINLIANG WANG $^{1}$, BOLUN CHANG ${ }^{2}$ and LI ZHANG ${ }^{1}$ \\ ${ }^{1}$ Department of Orthopedics, The Third Hospital of Hebei Medical University, Shijiazhuang, Hebei 050051; \\ ${ }^{2}$ Department of Orthopedics, Hebei Provincial Hospital of Traditional Chinese Medicine, \\ Shijiazhuang, Hebei 050011, P.R. China
}

Received April 22, 2019; Accepted October 11, 2019

DOI: $10.3892 /$ etm. 2020.9363

\begin{abstract}
Due to various limitations in the use of autologous bone and allogeneic bone in the repair of bone defects, the use of synthetic bone graft substitute has become a hot topic in orthopedic surgery and repair medicine. A total of 53 patients treated for trauma-induced metacarpal bone defects were recruited. These patients were divided into the $\mathrm{TiAl}_{6} \mathrm{~V}_{4}$ titanium alloy implantation group (group A) and the autologous bone graft group (group B). The symptoms of patients in the two groups were closely observed and followed up. The operation time, time to bone fusion, post-surgical pain [visual analog scale (VAS) scores], hand function recovery [total active flexion scale (TAFS) scores] and complications were compared between the two groups. Following surgery, none of the patients had necrosis of fingers or bone non-union. The recovery was rated as excellent and good in up to $91.6 \%$ of patients, indicating high clinical efficacy. Compared with the use of autologous bone grafting as the gold standard (group B), there was no significant difference in the excellent and good recovery rate based on TAFS scores at 16 weeks after surgery (91.7 vs. $89.7 \%, \mathrm{P}>0.05)$, and there was also no significant difference in the incidence of post-operative complications (33.3 vs. $41.3 \%, \mathrm{P}>0.05)$. The operation time $(82.08 \pm 6.64 \mathrm{~min})$, time to bone fusion $(7.75 \pm 1.73$ weeks) and VAS scores at 3 days after surgery were all significantly lower in group A than in group $\mathrm{B}(\mathrm{P}<0.05)$. The values of group B were $104.69 \pm 8.63$ min, $9.17 \pm 2.78$ weeks and $[5(5,6)]$, respectively. However, the hospitalization cost $(22,657.8 \pm 1,595.4 ¥)$ was significantly higher than that in group $\mathrm{B}(14,808.2 \pm 2,291.3 ¥ ; \mathrm{P}<0.05)$. In conclusion, the use of titanium alloy implantation may avoid new injury to the donor site, reduce the operation time and
\end{abstract}

Correspondence to: Dr Li Zhang, Department of Orthopedics, The Third Hospital of Hebei Medical University, 102 Youyi North Street, Shijiazhuang, Hebei 050051, P.R. China

E-mail: zhanglithhmu@163.com

Key words: metacarpal bone defects, titanium alloy implantation for metacarpal bone defects, autologous bone grafting, clinical effect post-operative pain and accelerate bone fusion. Therefore, this method is worthy of popularization for defective bone reconstruction and recovery in the clinic.

\section{Introduction}

An increasing number of cases of phalangeal defects caused by surgical defects, palm defects or trauma, congenital factors, malignant tumors and inflammation are encountered in the clinic (1-3). The unique anatomical structure of fingertips enables humans to feel sensation and to perform fine processing and grasping functions $(4,5)$. Therefore, reconstruction and restoration of metacarpal bone defects not only requires repair of the wound surface but also to restore good fingertip sensation. Finger length and aesthetic appearance also require to be maintained (6,7). Repair of metacarpal defects has long been a difficult challenge in plastic surgery (8).

Several methods may be used to treat bone defects, including surgical treatment using autogenous, heterogeneous and synthetic bone graft substitutes (9-11); furthermore, gene therapy $(12)$ and growth factory therapy $(13,14)$ may be employed to accelerate bone growth and fusion. At present, orthopaedic surgery using bone transplantation remains the most commonly used method for repairing bone defects $(15,16)$. Autogenous bone transplantation is considered the gold standard of bone transplantation (17), although it has the disadvantages of limited bone, potential risk of drug delivery sites and long-term hospitalization time $(18,19)$. Allogeneic bone transplantation is usually associated with immune response and risk of disease transmission (20). Bone grafts and substitutes are the most promising materials for bone defect repair and bone implantation and they are also the focus of relevant research $(21,22)$.

It has been indicated that titanium alloys have the advantages of light weight, good ductility, corrosion resistance and high bone integration. Titanium alloys are now widely used in orthopaedic and dental bone transplantation $(23,24)$. The present study was a retrospective cohort study of autogenous bone transplantation for the repair of metacarpal defects. Its aim was to explore the safety and clinical effect of titanium alloy implantation in repairing metacarpal bone defect in order to improve the clinical efficacy of bone transplantation. 


\section{Subjects and methods}

Baseline information. A total of 64 cases of open metacarpal bone defect treated with autologous bone graft or titanium alloy implantation at The Third Hospital of Hebei Medical University (Shijiazhuang, China) between June 2014 and December 2017 were included in the present study. The inclusion criteria were as follows: Open metacarpal bone defects within 3 weeks and one-stage debridement and vacuum sealing drainage with a fresh wound surface. The exclusion criteria were as follows: i) Age $<18$ years; ii) proper digital artery defects; iii) proper digital nerve defects; iv) combined with severe cardiovascular and cerebrovascular, kidney, liver and hematopoietic diseases and endocrine system diseases, or mental illnesses; v) severe brain injury and closed combined thoracoabdominal injuries. Doctors and patients worked together to formulate the surgical plan. Considerations included pain tolerance of the patient, surgical tolerance of the patient, the economic situation of the family of the patient and the patient's willingness to undergo surgery. Patients with pain, low tolerance to surgery and better economic conditions were recommended to opt for new materials used in the surgery. During the study, 5 cases dropped out and 8 cases were lost to follow-up. Hence, 53 patients were finally recruited. There were 24 cases in the titanium alloy implantation group (group A) and 29 cases in the autologous bone grafting group (group B). Among these 53 cases, there were 41 males and 12 females aged 21-56 years with an average of $36.54 \pm 9.56$ years. A total of 31 cases had phalangeal bone defects and 22 cases had metacarpal bone defects.

Surgical procedures. The implant in group A received titanium alloy implants (Chinese patent no. 201620201366.X). The surgical procedure was as follows: Brachial plexus blockage was performed. An incision of appropriate length was made on the dorsal side of the phalange for phalangeal defects or on the dorsum of hands for metacarpal bone defects (Fig. 1A). The extensor tendon was tracted to expose the fractured bone and bone defects (Fig. 1B). Contaminated and non-vital tissues were removed within the surgical field. The surrounding hardened edge was removed with bone nibbling forceps. The edges of the fractured end were ground flat with a bonesaw and flushed with normal saline-hydrogen peroxide. The wound was soaked in benzalkonium chloride for $10 \mathrm{~min}$. The medullary cavity of phalange (or metacarpal bone) was dilated to accommodate the proximal shaft of the prosthesis. Next, the reamer was inserted to dilate the medullary cavity to accommodate the distal shaft of the prosthesis (Fig. 1C). After trial insertion of the prosthesis and determination of the proper size, the prosthesis to be installed was taken out and bone cement was applied to it (Fig. 1D). The proximal prosthesis was first inserted, then the distal prosthesis. The prosthesis was reduced, waiting for the hardening of the bone cement 10 min later (Fig. 1E). Finally, after X-ray film acceptance, the extensor tendon was realigned and the incision was sutured layer by layer using non-invasive thread (Fig. 1F).

Patients in group B received brachial plexus blockage. For the harvesting of the iliac bone, epidural anesthesia or local anesthesia was given. An appropriate length incision was taken from the dorsal side of the phalanx, and an appropriate length incision a was taken from the dorsal side of the metacarpus
(Fig. 2A). The tendon was stretched to expose the broken bone and bone defect site (Fig. 2B), and the contaminated and lifeless tissue in the operation field was removed. The sclerotic edge around the broken end was removed using bone biting forceps, and the edge of the broken end was polished and leveled with a bone saw, washed with normal saline hydrogen peroxide, and soaked with benzalkonium chloride for $10 \mathrm{~min}$. Then, the pulp cavity of phalanx (or metacarpal bone) was expanded to accommodate the proximal stem of prosthesis, and then the reamer was inserted to enlarge the medullary cavity to accommodate the distal stem of prosthesis (Fig. 2C). The bone needed for bone grafting is typically autologous iliac bone (Fig. 2D). In cases with relatively few bone defects, distal radius can also be selected. When the iliac bone is removed, the bone block should be slightly longer than the defect area by $0.5-1 \mathrm{~cm}$, so that the two ends of the bone block are cut into small wedges and embedded into the marrow cavity at the fracture end. If there is only one broken end (such as end segment defect), one end is cut into a wedge shape and inserted into the medullary cavity near the fracture end, which not only increases the contact area but also increases the stability (Fig. 2E). The periosteum of the donor site was repaired after removal of the bone. According to the specific situation, steel plate, screw or Kirschner wire were selected for fixation, and then X-ray film was taken to accept (Fig. 2F). In order to reduce the tension of the skin suture, cross or parallel Kirschner wires were used to fix the defects of the middle and distal segments of the fingers. Finally, the incision was sutured layer by layer with non-invasive suture.

Post-operative treatment. Patients in the two groups received routine antibiotics treatment for 5-7 days and detumescence with mannitol for 3-5 days. The affected limb was elevated to facilitate detumescence. The patients received frontal and oblique X-rays of the affected hand at 1 day after surgery to assess bone length after filling in the bone defect and the position of the implant or bone graft. The patients wore a plaster caster support for 4-6 weeks. The patients began active and passive functional exercise at 1 month after surgery under guidance. Group A began partial weight-bearing exercise at 1 month after surgery and group $B$ began partial weight-bearing exercise at 3 months after surgery according to the extent of bone fusion and complete weight-bearing exercise after the bone fracture completely healed.

Observation indicators. i) Post-operative pain intensity: Pain was assessed by using the visual analog pain scale (VAS) (25) at day 3 and day 7 after surgery, respectively, on which 10 points represented the maximal pain. ii) Operation time: The operation time was the time span from the start of surgery to the completion of incision suturing. iii) Time to bone fusion: The patients were re-examined by X-rays at week 4, 8, 10, 12 and 16 after surgery to assess bone fusion. iv) Functional recovery of the hand: Functional recovery of the hand was assessed using the total active flexion scale (TAFS) developed by the American Society for Surgery of the Hand (26). According to the scoring criteria of TAFS, 'Excellent' recovery was defined as flexion of the metacarpophalangeal joint and interphalangeal joint by $>220^{\circ}$, 'good' as $180-220^{\circ}$ and 'poor' as $<180^{\circ}$. v) Surgical complications: Infection of incision site, necrosis of the fingertip, malunion and adhesion were recorded. 


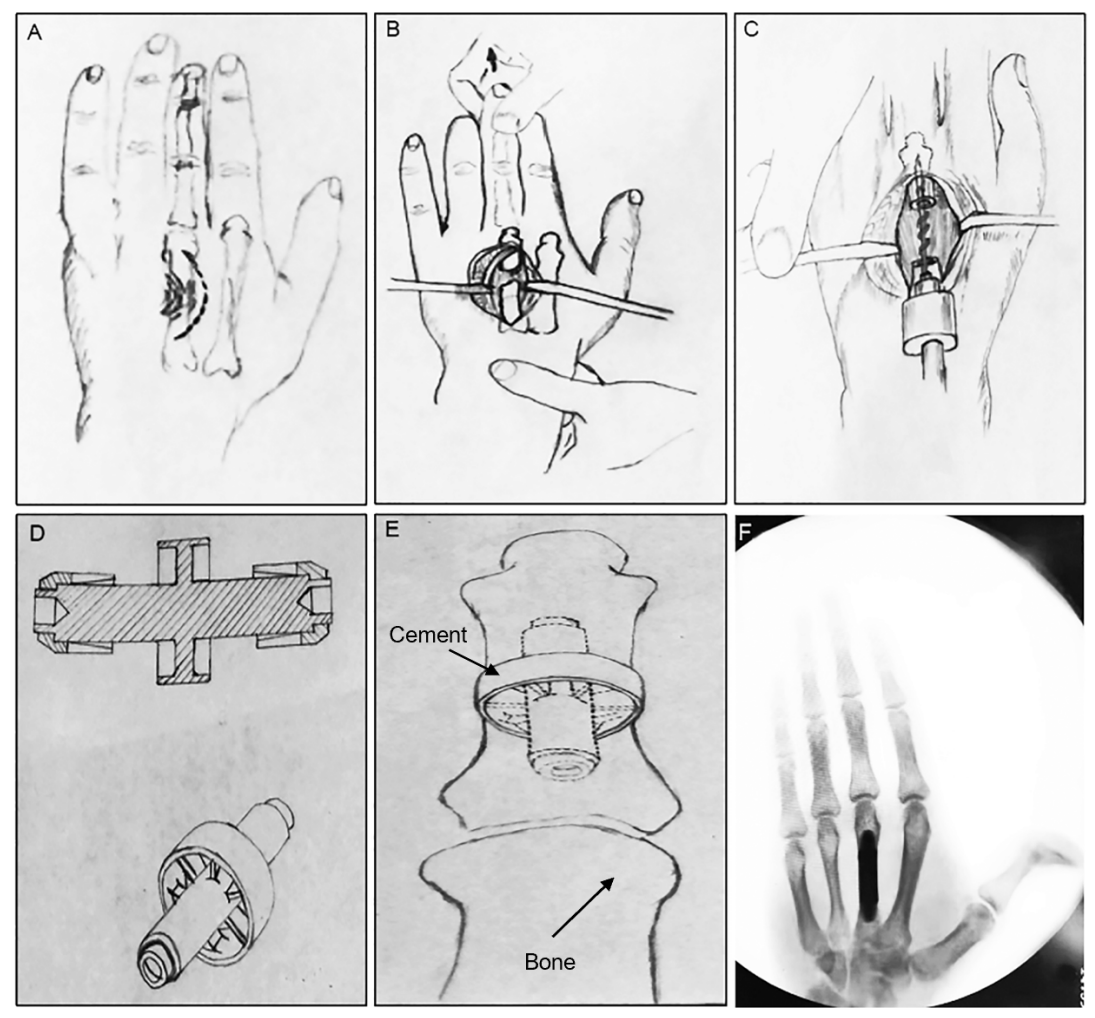

Figure 1. The implant in group A was titanium alloy implants. (A-C) Drawings illustrating the initial steps of the surgical procedure. (A) Defect of the third metacarpal bone with the skin incision indicated by a dotted line. (B) Incision of skin and subcutaneous tissue to expose fracture ends. (C) Treatment of fracture ends and medullary cavity. (D) Self-designed bone defect prosthesis. (E) Drawing illustrating the fixation of the prosthesis to the metacarpal defect with bone cement. (F) Repair of metacarpal bone defect with self-made prosthesis and bone cement.

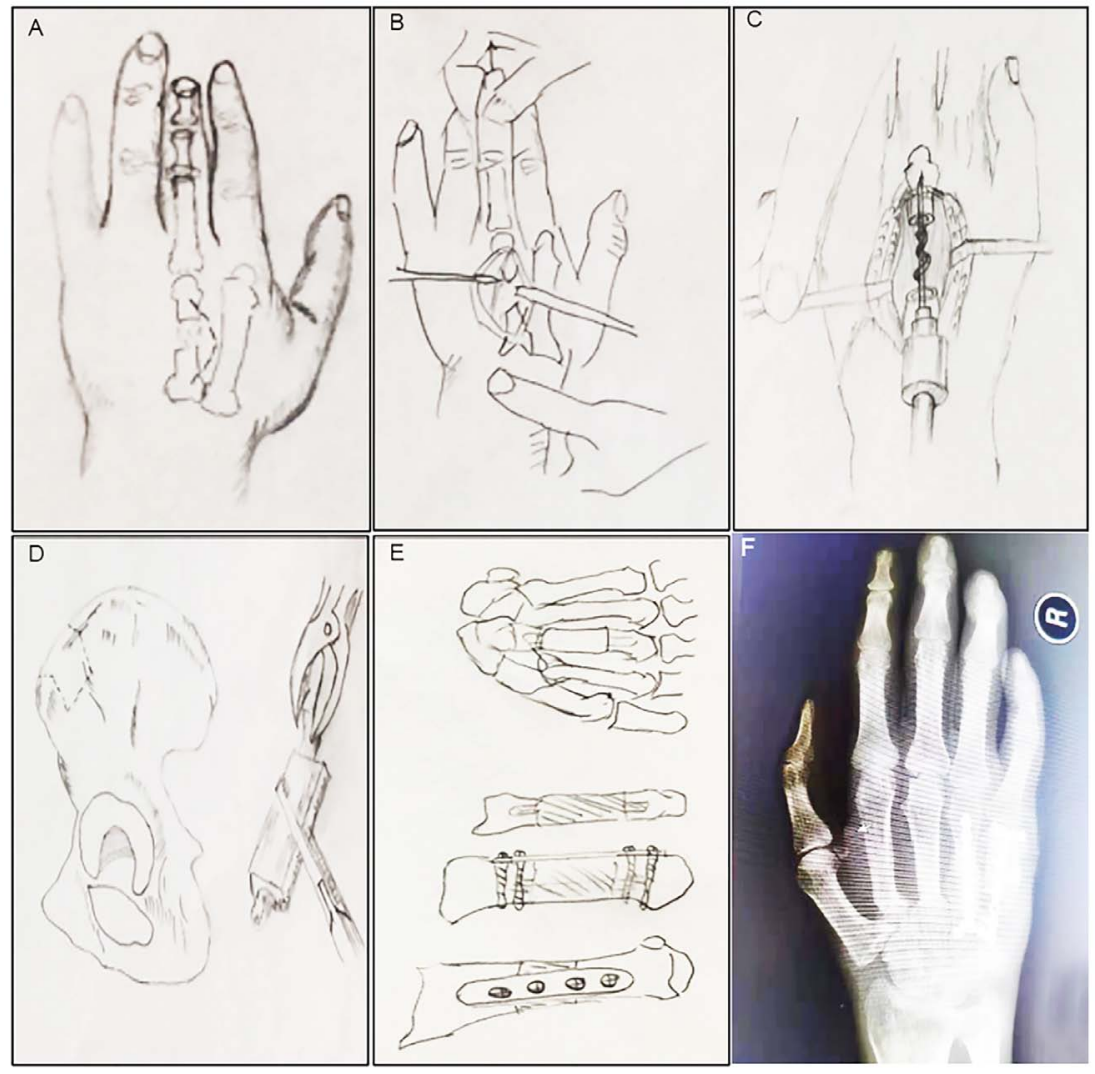

Figure 2. Patients in group B received brachial plexus blockage. (A-E) Drawings illustrating the steps of the surgical procedure. (A) Defect of the third metacarpal bone with the skin incision indicated by a dotted line. (B) Incision of skin and subcutaneous tissue to expose fracture ends. (C) Treatment of fracture ends and medullary cavity. (D) Bone was taken from the ilium wing and trimmed to a suitable size and shape. (E) The pruned iliac bone was implanted into the defect of the metacarpal bone and fixed with plate and screw. (F) Repositioning and internal fixation of the fourth and fifth metacarpal bones of the right hand. 
Table I. Comparison of baseline information between the two groups.

\begin{tabular}{|c|c|c|c|c|}
\hline Item & Group A (n=24) & Group B $(n=29)$ & $\chi^{2} / \mathrm{t}$ statistic & P-value \\
\hline Gender & & & 0.082 & 0.775 \\
\hline Male & $19(79.1)$ & $22(75.9)$ & & \\
\hline Female & $5(20.8)$ & $7(24.1)$ & & \\
\hline Cause of injury & & & 0.592 & 0.744 \\
\hline Crush injury & $6(25.0)$ & $9(31.0)$ & & \\
\hline Cut injury & $8(33.3)$ & $7(24.1)$ & & \\
\hline Motor vehicle collision & $10(41.7)$ & $13(44.9)$ & & \\
\hline Site of injury & & & 0.290 & 0.590 \\
\hline Phalange & $15(62.5)$ & $16(55.2)$ & & \\
\hline Metacarpal bone & $9(37.5)$ & $13(44.8)$ & & \\
\hline Age (years) & $37.58 \pm 8.47$ & $35.69 \pm 10.43$ & 0.715 & 0.478 \\
\hline Defect area $\left(\mathrm{mm}^{2}\right)$ & $267.3 \pm 85.9$ & $243.8 \pm 94.7$ & 0.946 & 0.344 \\
\hline
\end{tabular}

Values are expressed as $\mathrm{n}(\%)$ or the mean \pm standard deviation. Groups: A (titanium implant), patients received titanium alloy implants; B (autologous bone grafting), patients received brachial plexus blockage.

Statistical analysis. SPSS 20.0 (IBM Corp.) was used for statistical analysis. Enumeration data were expressed as the $\mathrm{n}(\%)$ and the difference was compared by using the $\chi^{2}$ test. Continuous variables with a normal distribution (assessed using the Kolmogorov-Smirnov test) of data were expressed as the mean \pm standard deviation and differences were compared by using the t-test, while the median and inter-quartile range (P25, P75) were used to represent the continuous variables with a non-normal distribution, and the Kruskal-Wallis test was used to compare the differences. $\alpha=0.05, \mathrm{P}<0.05$ was considered to indicate a statistically significant difference.

\section{Results}

Baseline information of the two groups. Group A comprised 24 cases, including 19 males $(79.1 \%)$ and 5 females (20.8\%), who were aged 21-55 years with an average age of $37.58 \pm 8.47$ years. The average size of the area defect was $267.3 \pm 85.9 \mathrm{~mm}^{2}$. The causes of bone defects were crush injury in 6 cases $(25.0 \%)$, cut injury in 8 cases $(33.3 \%)$ and motor vehicle collisions in 10 cases $(41.7 \%)$. There were 15 cases $(62.5 \%)$ with phalangeal defects and 9 cases (37.5\%) with metacarpal bone defects. Group B comprised 29 cases, including 22 males (75.9\%) and 7 females (24.1\%), who were aged 21-56 years with an average age of $35.69 \pm 10.43$ years. The average size of the area defect was $243.8 \pm 94.7 \mathrm{~mm}^{2}$. The causes of bone defects were crush injury in 9 cases $(31.0 \%)$, cut injury in 8 cases $(24.1 \%)$ and motor vehicle collisions in 13 cases $(44.9 \%)$. There were 16 cases $(55.2 \%)$ with phalangeal defects and 13 cases $(44.8 \%)$ with metacarpal bone defects. The two groups were comparable regarding their baseline information without any significant differences $(P>0.05$, Table I).

Post-operative pain in the two groups. The VAS scores in the two groups at day 3 and day 7 after surgery are shown in Fig. 3 . At day 3 , the VAS score of group A [5(4,6)] was significantly

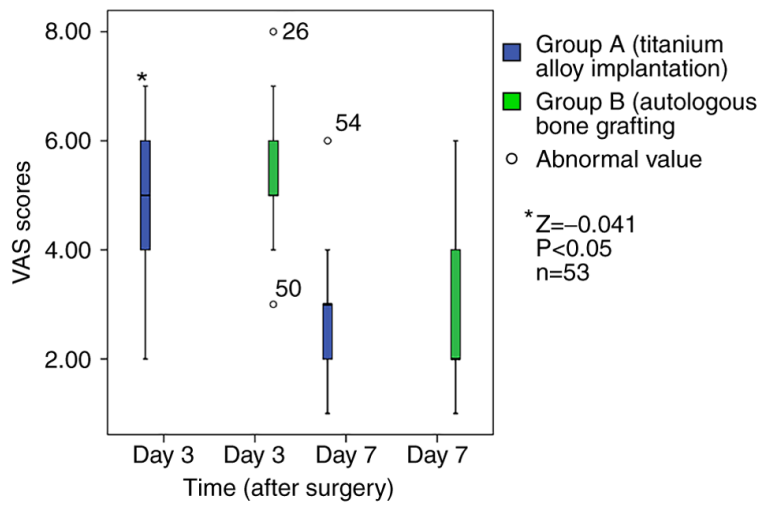

Figure 3. Comparison of VAS scores between the two groups at day 3 and day 7 after surgery. The circles indicate abnormal outlier values. Values are expressed as median and interquartile range. ${ }^{*} \mathrm{P}<0.05$ vs. Group B. $\mathrm{Z}=-0.014$. Groups: A (titanium implant), patients received titanium alloy implants $(n=24)$; B (autologous bone grafting), patients received brachial plexus blockage $(n=29)$. VAS, visual analog scale.

lower than that of group B $[5(5,6)](Z=-0.041, P<0.05)$. At day 7 , there was no significant difference in the VAS scores between the two groups ( $\mathrm{P}>0.05$; Table II). Patients in both groups with a higher pain score and lower pain tolerance were given pethidine as an analgesic aid within $24 \mathrm{~h}$.

Comparison of surgery and hospitalization costs between the two groups. All 53 cases included were fully prepared prior to surgery and all of the surgeries were successful. There were no interoperative or anesthetic complications. The average operation time was $82.08 \pm 6.64 \mathrm{~min}$ in group $\mathrm{A}$, which was significantly shorter than that in group B $(104.69 \pm 8.63 \mathrm{~min}$, $\mathrm{t}=-10.504, \mathrm{P}<0.001$; Fig. 4). In all patients, radiographs indicated satisfactory bone fusion. The average time to bone fusion was $7.75 \pm 1.73$ weeks in group $\mathrm{A}$, which was significantly shorter than that in group B $(9.17 \pm 2.78$ weeks; $\mathrm{t}=-2.182$, $\mathrm{P}<0.05$; Fig. 5). The average medical cost in group A was 
Table II. Comparison of VAS scores between the two groups at day 3 and day 7 after surgery.

\begin{tabular}{|c|c|c|c|c|}
\hline Day after surgery & Group A $(n=24)$ & Group B $(n=29)$ & t statistic & P-value \\
\hline 3 & $4.75 \pm 1.32$ & $5.51 \pm 1.58$ & -2.132 & 0.025 \\
\hline 7 & $2.75 \pm 1.07$ & $2.89 \pm 1.47$ & -0.406 & 0.686 \\
\hline
\end{tabular}

Groups: A (titanium implant), patients received titanium alloy implants; B (autologous bone grafting), patients received brachial plexus blockage.

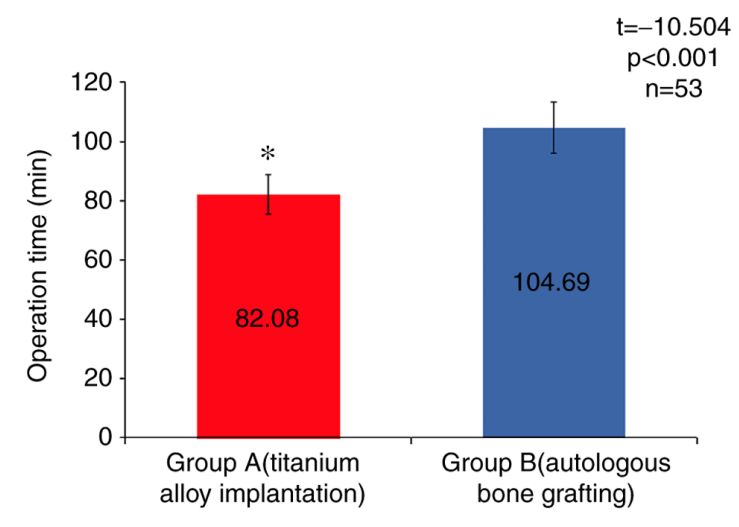

Figure 4. Comparison of operation time between the two groups. ${ }^{*} \mathrm{P}<0.001$, $\mathrm{t}=-10.504$. Groups: A (titanium implant), patients received titanium alloy implants ( $\mathrm{n}=24)$; B (autologous bone grafting), patients received brachial plexus blockage $(\mathrm{n}=29)$.

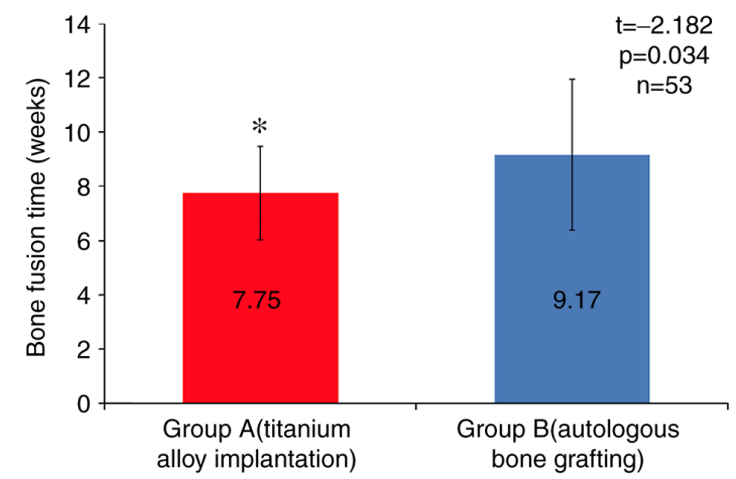

Figure 5. Comparison of time to bone fusion between the two groups. ${ }^{*} \mathrm{P}=0.034, \mathrm{t}=-2.182$. Groups: A (titanium implant), patients received titanium alloy implants $(\mathrm{n}=24)$; B (autologous bone grafting), patients received brachial plexus blockage $(n=29)$.

(22657.8 $\pm 1595.4 Y$ ), which was significantly higher than that in group B (14808.2 $\pm 2291.3 ¥, \mathrm{t}=144.169, \mathrm{P}<0.05$; Fig. 6).

Comparison ofTAFSscores between the two groups. Functional recovery of the hand was assessed by TAFS scoring 14 weeks postoperatively. As presented in Table III, group A comprised 15 cases (62.5\%) with excellent TAFS scores, 7 cases (29.2\%) with good TAFS scores and 2 cases (8.3\%) with poor TAFS scores. The overall excellent and good recovery rate was $91.7 \%$. In group B, there were 165 cases $(55.2 \%)$ with excellent TAFS scores, 10 cases (34.5\%) with good TAFS scores and 3 cases $(10.3 \%)$ with poor TAFS scores. The overall excellent

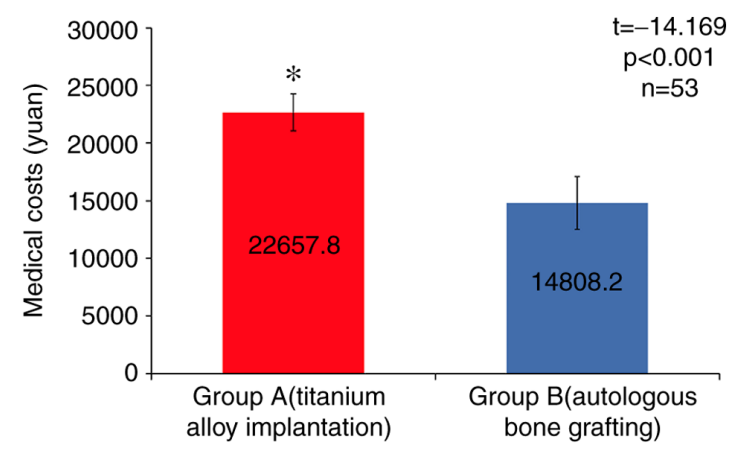

Figure 6. Comparison of hospitalization costs between the two groups. ${ }^{*} \mathrm{P}<0.001, \mathrm{t}=-14.169$. Groups: A (titanium implant), patients received titanium alloy implants $(n=24)$; B (autologous bone grafting), patients received brachial plexus blockage $(n=29)$.

and good recovery rate was $89.7 \%$. The $\chi^{2}$ test was used for comparison of excellent and good recovery rates between the two groups, and $\chi^{2}=0.062$ and $\mathrm{P}>0.05$ was obtained, indicating no significant difference (Table III).

Comparison of post-operative complications between the two groups. The major post-operative complications for patients with metacarpal bone defects included skin reddening and swelling, infection of the incision site, malfusion and loosening of internal fixation. For group A, the overall incidence of post-operative complications was $33.3 \%$, and that of group B was $41.3 \%$. The $\chi^{2}$ test provided $\chi^{2}=0.362$ and $\mathrm{P}>0.05$, indicating no significant difference (Table IV). All post-operative complications were treated symptomatically.

\section{Discussion}

With the rapid development of economy, transportation and construction industry, the number of patients with hand trauma is exhibiting yearly increases $(27,28)$. Studies indicate that hand injuries account for $25-30 \%$ of the total cases of traumatic surgery (29-31). Hand injuries are usually accompanied by bone and joint injuries. Maximization of the efficiency of the repair of bone and joint defects has been a major clinical challenge. Autografts, allografts and synthetic bone graft substitutes have been indicated to be effective in repairing bone defects (32). In the present study, autologous bone grafts $(n=29)$ and titanium alloy implants $(n=24)$ were respectively used to treat metacarpal bone defects in 53 patients who achieved good bone fusion, as well as hand appearance and 
Table III. Comparison of rating based on TAFS scores between the two groups 14 weeks post-operatively.

\begin{tabular}{lcrcccc}
\hline & \multicolumn{9}{c}{ Rating } & & & \\
Group & Excellent & \multicolumn{1}{c}{ Good } & Poor & Excellent and good & $\chi^{2}$ statistic & P-value \\
\hline A (n=24) & $15(62.5)$ & $7(29.2)$ & $2(8.3)$ & $22(91.7)$ & 0.062 & 0.803 \\
B (n=29) & $16(55.2)$ & $10(34.5)$ & $3(10.3)$ & $26(89.7)$ & & \\
\hline
\end{tabular}

Values are expressed as n (\%). Groups: A (titanium implant), patients received titanium alloy implants; B (autologous bone grafting), patients received brachial plexus blockage. TAFS, total active flexion scale.

Table IV. Comparison of post-operative complications between the two groups.

\begin{tabular}{lccccccr}
\hline \multicolumn{7}{c}{ Complications } \\
Group & $\begin{array}{c}\text { Skin reddening } \\
\text { and swelling }\end{array}$ & $\begin{array}{c}\text { Incision } \\
\text { infection }\end{array}$ & Malfusion & $\begin{array}{c}\text { Loosening of } \\
\text { internal fixation }\end{array}$ & Incidence & $\chi^{2}$ statistic & P-value \\
\hline A (n=24) & $3(12.5)$ & $2(8.3)$ & $1(4.2)$ & $2(8.3)$ & $8(33.3)$ & 0.362 & 0.547 \\
B (n=29) & $4(13.8)$ & $3(10.3)$ & $2(6.9)$ & $3(10.3)$ & $2(41.3)$ & & \\
\hline
\end{tabular}

Values are expressed as $\mathrm{n}(\%)$. Groups: A (titanium implant), patients received titanium alloy implants; B (autologous bone grafting), patients received brachial plexus blockage.

functional recovery. The excellent and good recovery rate reached up to $91.6 \%$.

Due to their osteoconductivity, osteoinductivity and osteogenesis, autogenous bone grafts are able to integrate into the host bone more rapidly and completely compared with synthetic bone substitutes. Autogenous bone grafts are generally considered the gold standard for repairing bone defects and are also the benchmark for evaluating other bone grafts and bone substitutes (15). However, it is not always possible to use autologous bone grafts for bone defect repair (32). Apart from the intrinsic limitations of this procedure (restricted bone resources, longer operation time, pain and infection of the donor site), population ageing and prevalence of diabetes also bring a great challenge to autologous bone grafting. In a word, autologous bone grafting cannot satisfy clinical requirements (33). Bone transplantation is gradually changing from natural grafts to synthetic bone substitutes and biological factors. Hung et al (34) performed a 13-year follow-up of 24 patients receiving surgery for osteosarcoma of the hand. The results indicated that synthetic bone graft substitute was a safe and effective option for the treatment of hand chondroma, with good functional and radiological effects and a low complication rate (34).

In the present study, a retrospective cohort study of patients undergoing autogenous bone transplantation and titanium alloy implantation to repair metacarpal defects was performed, and the safety and clinical outcomes of the two types of surgery were compared. The titanium alloy implants used are made of $\operatorname{TiAl}_{6} \mathrm{~V}_{4}$. Customized joint prostheses are usually manufactured by rapid prototyping and alloy casting techniques. Porous titanium and titanium alloys have been indicated to have excellent mechanical properties, enabling them to be used as permanent orthopedic implants under load-bearing conditions (35). Titanium alloy implants for repairing metacarpal defects have a similar elastic modulus, high tissue compatibility and the same anatomical structure as real metacarpophalangeal joints. Therefore, it is an ideal option for individualized repair and prosthesis replacement for traumatic hand bone defects (36). The present results suggested that, compared with autologous bone grafting as the gold standard, the excellent and good recovery rate of the titanium alloy implantation group at 16 weeks was comparable (91.7\% vs. $89.7 \%, \mathrm{P}>0.05$ ). There was also no significant difference in the incidence of post-operative complications $(33.3 \%$ vs. $41.3 \%, \mathrm{P}>0.05)$. Patients with post-operative complications received symptomatic treatment and the symptoms were soon relieved without causing any adverse impact on treatment and recovery. The present study indicated that the two procedures were comparable in terms of post-operative functional recovery and incidence of complications.

Furthermore, the titanium alloy implant is superior to autologous bone grafting in the following four aspects: i) Avoidance of new defects and complications of the donor site, which is of high importance for elderly and feeble patients, as well as those with poor immunity (37); ii) the operation time was shortened and there was a significant difference in the operation time between the groups A and B $(82.08 \pm 6.64 \mathrm{~min}$ vs. $104.69 \pm 8.63 \mathrm{~min}, \mathrm{P}<0.05)$; iii) the time to bone fusion was shortened and the two groups exhibited a significant difference $(7.75 \pm 1.73$ weeks vs. $9.17 \pm 2.78$ weeks, $\mathrm{P}<0.05)$; iv) the pain was relieved and there was a significant difference in VAS scores at day 3 after surgery between the two groups $(4.75 \pm 1.32$ vs. $5.51 \pm 1.58, \mathrm{P}<0.05)$.

The hospitalization costs of the two groups were compared, indicating that the costs in the group receiving titanium alloy 
implantation to treat metacarpophalangeal bone defect were significantly higher than those in the autogenous bone transplantation group and the difference was statistically significant. This points at the requirement to constantly improve the proficiency and quality of surgery in future clinical practice, shorten the hospitalization time of patients and avoid complications, so as to reduce hospitalization costs of patients, and better promote and popularize this technology.

To conclude, titanium alloy implantation and autologous bone grafting may achieve similar clinical effects for the repair of metacarpal bone defects and cause few complications. The two procedures are reliable methods for the repair of metacarpal bone defects. However, the present study has the following limitations: The sample size was small, as this method was only introduced recently and no long-term follow-up was performed. Thus, a retrospective, non-randomized controlled study was performed. It appears that titanium alloy implantation is a good option, as it shortens the operation time and time to bone fusion, relieves the pain, avoids injury to the donor site and improves the appearance and functions of the hand. This procedure is therefore worthy of wider application. As the biological implants and surgical technique are improved and upgraded, this procedure will have a broader application scope in the future.

\section{Acknowledgements}

Not applicable.

\section{Funding}

No funding was received.

\section{Availability of data and materials}

The datasets used and/or analyzed during the current study are available from the corresponding author on reasonable request.

\section{Authors' contributions}

$\mathrm{LZ}$ was responsible for the conception and design of the study. $\mathrm{LZ}$ and $\mathrm{YZ}$ prepared the manuscript and revised the final draft of the manuscript. YZ, JW and BC performed the experiments and analyzed the data. All authors read and approved the final version of the manuscript.

\section{Ethics approval and consent to participate}

The protocol was approved by the ethics committee of The Third Hospital of Hebei Medical University (Shijiazhuang, China). Written informed consent was obtained from all patients.

\section{Patient consent for publication}

Not applicable.

\section{Competing interests}

The authors declare that they have no competing interests.

\section{References}

1. WHO: Injuries and violence: The facts 2014. World Health Organization, Geneva, 2014.

2. Mauffrey C, Barlow BT and Smith W: Management of segmental bone defects. J Am Acad Orthop Surg 23: 143-53, 2015.

3. Lu H, Liu Y, Guo J, Wu H, Wang J and Wu G: Biomaterials with antibacterial and osteoinductive properties to repair infected bone defects. Int J Mol Sci 17: 334, 2016.

4. Güleç A, Özdemir A, Durgut F, Yildirim A and Acar MA: Comparison of innervated digital artery perforator flap versus homodigital reverse flow flap techniques for fingertip reconstruction. J Hand Surg Am 44: 801.e1-801.e6, 2019.

5. García-Gareta E, Coathup MJ and Blunn GW: Osteoinduction of bone grafting materials for bone repair and regeneration. Bone 81: 112-121, 2015.

6. Panattoni JB, De Ona IR and Ahmed MM: Reconstruction of fingertip injuries: Surgical tips and avoiding complications. J Hand Surg Am 40: 1016-1024, 2015.

7. Germann G, Rudolf KD, Levin SL and Hrabowski M: Fingertip and thumb tip wounds: Changing algorithms for sensation, aesthetics, and function. J Hand Surg Am 42: 274-284, 2017.

8. Özcanlı H, Bektaş G, Cavit A, Duymaz A and Coşkunfırat OK: Reconstruction of fingertip defects with digital artery perforator flap. Acta Orthop Traumatol Turc 49: 18-22, 2015.

9. Griffin KS, Davis KM, McKinley TO, Anglen JO, Chu TMG, Boerckel JD and Kacena MA: Evolution of bone grafting: Bone grafts and tissue engineering strategies for vascularized bone regeneration. Clinic Rev Bone Miner Metab 13: 232-244, 2015.

10. Bhumiratana S, Bernhard JC, Alfi DM, Yeager K, Eton RE, Bova J, Shah F, Gimble JM, Lopez MJ, Eisig SB and Vunjak-Novakovic G: Tissue-engineered autologous grafts for facial bone reconstruction. Sci Transl Med 8: 343ra83-343ra83, 2016.

11. Tang D, Tare RS, Yang LY, Williams DF, Ou KL and Oreffo RO: Biofabrication of bone tissue: Approaches, challenges and translation for bone regeneration. Biomaterials 83: 363-382, 2016.

12. Evans $\mathrm{CH}$ and Huard J: Gene therapy approaches to regenerating the musculoskeletal system. Nat Rev Rheumatol 11: 234-242, 2015.

13. García JR, Clark AY and García AJ: Integrin-specific hydrogels functionalized with VEGF for vascularization and bone regeneration of critical-size bone defects. J Biomed Mater Res A 104: 889-900, 2016.

14. Martino MM, Briquez PS, Maruyama K and Hubbell JA: Extracellular matrix-inspired growth factor delivery systems for bone regeneration. Adv Drug Deliv Rev 94: 41-52, 2015.

15. Egol KA, Nauth A, Lee M, Pape HC, Watson JT and Borrelli J Jr: Bone grafting: Sourcing, timing, strategies, and alternatives. J Orthop Trauma 29 (Suppl 12): S10-S14, 2015.

16. A.M.J.J.o.S.M. Ahmad Oryan, D. Studies, An Overview on Bone Tissue Engineering and Regenerative Medicine: Current Challenges, Future Directions and Strategies.

17. Campana V, Milano G, Pagano E, Barba M, Cicione C, Salonna G, Lattanzi W and Logroscino G: Bone substitutes in orthopaedic surgery: From basic science to clinical practice. J Mater Sci Mater Med 25: 2445-2461, 2014.

18. Gruskay JA, Basques BA, Bohl DD, Webb ML and Grauer JN: Short-term adverse events, length of stay, and readmission after iliac crest bone graft for spinal fusion. Spine (Phila Pa 1976) 39: 1718-1724, 2014.

19. Heneghan HM and McCabe JP: Use of autologous bone graft in anterior cervical decompression: Morbidity \& quality of life analysis. BMC Musculoskelet Disord 10: 158, 2009.

20. Hernigou P: Bone transplantation and tissue engineering, part III: Allografts, bone grafting and bone banking in the twentieth century. Int Orthop 39: 577-587, 2015.

21. Agarwal R and García AJ: Biomaterial strategies for engineering implants for enhanced osseointegration and bone repair. Adv Drug Deliv Rev 94: 53-62, 2015.

22. Beuriat PA, Szathmari A, Grassiot B, Di Rocco F and Mottolese C: Why a hydroxyapatite cranioplasty can be used to repair a cranial bone defect in children: Experience of 19 cases. Neurochirurgie 62: 251-257, 2016 (In French).

23. Lindsey RW, Gugala Z, Milne E, Sun M, Gannon FH and Latta LL: The efficacy of cylindrical titanium mesh cage for the reconstruction of a critical-size canine segmental femoral diaphyseal defect. J Orthop Res 24: 1438-1453, 2010. 
24. Ryan GE, Pandit AS and Apatsidis DP: Porous titanium scaffolds fabricated using a rapid prototyping and powder metallurgy technique. Biomaterials 29: 3625-3635, 2008.

25. Lin SY, Huang PJ, Huang HT, Chen CH, Cheng YM and Fu YC: An alternative technique for the management of phalangeal enchondromas with pathologic fractures. J Hand Surg Am 38: 104-109, 2013.

26. Soni A, Gulati A, Bassi JL, Singh D and Saini UC: Outcome of closed ipsilateral metacarpal fractures treated with mini fragment plates and screws: A prospective study. Comparative Study 13: 29-33, 2012.

27. Hsia RY, Nath JB and Baker LC: California emergency department visit rates for medical conditions increased while visit rates for injuries fell, 2005-11. Health Aff (Millwood) 34: 621-626, 2015.

28. De Putter CE, van Beeck EF, Polinder S, Panneman MJ, Burdorf A, Hovius SE and Selles RW: Healthcare costs and productivity costs of hand and wrist injuries by external cause: A population-based study in working-age adults in the period 2008-2012. Injury 47: 1478-1482, 2017.

29. Dias JJ and Garcia-Elias M: Hand injury costs. Injury 37: 1071-1077, 2006.

30. Grivna M, Eid HO and Abu-Zidan FM: Epidemiology of isolated hand injuries in the United Arab Emirates. World J Orthop 7: $570-776,2016$.

31. Chau N, Gauchard GC, Siegfried C, Benamghar L, Dangelzer JL, Français M, Jacquin R, Sourdot A, Perrin PP and Mur JM: Relationships of job, age, and life conditions with the causes and severity of occupational injuries in construction workers. Int Arch Occup Environ Health 77: 60-66, 2004.
32. Scheker LR and Becker GW: Distal finger replantation. J Hand Surg Am 36: 521-528, 2011.

33. Wang W and Yeung KWK: Bone grafts and biomaterials substitutes for bone defect repair: A review. Bioact Mater 2: 224-247, 2017.

34. Hung YW, Ko WS, Liu WH, Chow CS, Kwok YY, Wong CW, Tse WL and Ho PC: Local review of treatment of hand enchondroma (artificial bone substitute versus autologous bone graft) in a tertiary referral centre: 13 years' experience. Hong Kong Med J 21: 217-223, 2015.

35. Heinl P, Rottmair A, Koerner C and Singer RF: Cellular Titanium by Selective Electron Beam Melting. Adv Eng Mater 9: 360-364, 2010.

36. Saulacic N, Bosshardt DD, Bornstein MM, Berner S and Buser D: Bone apposition to a titanium-zirconium alloy implant, as compared to two other titanium-containing implants. Eur Cell Mater 23: 273-288, 2012.

37. Liodaki E, Kraemer R, Mailaender P and Stang F: The use of bone graft substitute in hand surgery: A prospective observational study. Medicine (Baltimore) 95: e3631, 2016.

This work is licensed under a Creative Commons Attribution-NonCommercial-NoDerivatives 4.0 International (CC BY-NC-ND 4.0) License. 